\title{
Communication by Design - (Mis)Understanding the Purpose
}

Preliminary communication _ DOI 10.22522/cmr20180131 _ received on 22 April 2018 UDK: $7.05: 316.772$

\section{Sanja Rocco, M.Sc.}

Zagreb School of Business, Croatia. Email: sanja.rocco@pvzg.hr

\section{Abstract}

Researchers from different fields of marketing, communication and management often see the role of design at the end of the process. However, design should be managed and involved in the decisionmaking process from the beginning, the same as other important components of any business. The main purpose of design is communication, whether it is visual communication design, product design or service design. No matter how complex, design should first send a message that is clear and understandable, whether it is a package or a product, a signage in public space or a website. The topic of this paper is (visual) communication design. The need for good communication design is greater than ever, because our everyday life depends on images and their interpretation, particularly with the fast development of communication technologies. Bad communication design can cause serious communication problems, pollute our environment, or even devalue the public space. However, strong personal presence is not desirable and necessary in communication designers' work, as their main purpose and responsibility is to deliver the message from their clients to the target audience.

Keywords: design, message, visual communication, images, communication problems 


\section{Introduction and Previous Research Analysis}

We are surrounded by design in our everyday lives. Especially with the growing digital technology, visual images are almost everywhere in our environment and most of them are professionally designed. But what is the main purpose, what is the meaning of design? We are not the first to ask this question. According to the complexity of design as a term, the approaches to this question are also different. We will first analyse some of previous research.

Academic research of value added through product design is long-standing and comprehensive, but its broader contribution to designing processes and especially services came to attention recently. The impact of visual communication design on users usually concentrates on their decision making process of buying the product, although its influence is far more complex and unpredictable; it affects many senses and even their mind. More recent emphasis has been put on design methods applied to the management processes and strategies as well as on innovation of products and services by design.

Candi (2005) analysed several previous researches and summarized different segmentations of design dimensions (Dreyfuss, 1967; Papanek, 1984; Kotler, Rath, 1984; Ulrich, Eppinger, 2003; Norman, 2004). A comparison of these taxonomies shows that they have a great deal in common. The three-dimensional taxonomy of design suggested by Norman (2004) provides a convenient and appropriate framework for classifying design focus and evaluating design emphasis since it successfully encompasses all aspects found in the other taxonomies.

The three dimensions of design are defined as follows:

D1. Visceral design appeals to the senses (Norman, 2004).

Berkowitz (1987) conducted studies that demonstrate that the form or shape of a product affects beliefs about the product, and these beliefs in turn are likely to affect consumer preferences. Creusen and Schoormans (2005) confirm the influence of appearance on consumer choice of products based on an empirical study. Yamamoto and Lambert (1994) show that appearance has an influence on customer preference even for industrial products. Dreyfuss (1967), Ulrich and Eppinger (2003) and Kotler and Rath (1984) emphasize the importance of appearance, i.e. the form, line, proportion and colour which are used to integrate a product into a pleasing whole, with the primary goal of product differentiation. 
D2. Behavioural design is about usability and performance. More specifically, the four components of good behavioural design are function, understandability, usability and physical feel (Norman, 2002; Norman, 2004). Dreyfuss (1967) and Papanek (1984) emphasise the importance of utility, or the intuitiveness of user interfaces. Dreyfuss (1967) also emphasises the importance of low costs and ease of maintenance facilitated by design which communicates how products are to be maintained and repaired. Ulrich and Eppinger (2003) expand on Dreyfuss's concern for costs by taking into account environmental factors and unnecessary features. Kotler and Rath (1984) argue that design must take into account cost constraints. Papanek (1984) describes method as the interaction of tools, processes and materials to reach a functional goal. Kotler and Rath (1984) include quality, durability and performance as major elements of design.

D3. Reflective design is about message, culture and the meaning of a product or service. Stuart and Tax (2004) define the design of service products as the design of customer experiences, which resonates with Norman's (2004) concept of reflective design. Dreyfuss (1967) argues that product design should communicate corporate design philosophy and mission. Ulrich and Eppinger (2003) discuss emotional appeal which encompasses factors like attractiveness, pride of ownership and the image of quality. Papanek (1984) includes the economic, psychological, spiritual, social, technological and intellectual needs of human beings in his taxonomy of design.

All three dimensions of design are in essence concerned with aspects of the interface between humans and products or services; communication is the essence of design.

The first stage of a design process, as explained by Tim Brown (2009), is often discovering the importance of constraints and establishing a framework for evaluation. These constraints can best be visualized in terms of three overlapping criteria for successful ideas: feasibility (what is functionally possible within the near future), viability (what is likely to become part of a sustainable business model) and desirability (what makes sense to people and for people). While a competent designer will resolve each of these three constraints, a design thinker will bring them into a harmonious balance.

Design is a process that turns a brief or requirement into a finished product or design solution. The design process can be said to comprise seven stages: define, research, ideate, prototype, 
select, implement and learn. Each of these requires design thinking. The design process engages a high degree of creativity but in a way that is controlled and directed by the process so that it is channelled towards producing a viable, practical solution to the design problem, meeting or exceeding the stated aims of the brief (Ambrose, Harris, 2010, p. 11).

By analysing different cases of design from past and today, Almquist and Lupton (2009, p. 14) come to a conclusion that an ecology of meanings and affordances offers paradigms for understanding the complex relations among things, persons, and environments, in designs both from the past and for the future, inviting not only a holistic mode of inquiry towards human artefacts and their users but also an attitude of concern, care, and engagement in response to the interlocking habitats of persons, things, rituals, and resources that surround and define us. They suggest that the task of design research - both research in the service of the design process, and research into the role design plays in contemporary and historical life - should be oriented around the common ground between use, meaning, and affordance, which is also the common ground between designers and "users".

According to Frascara (2004), designers - as opposed to artists - are not normally the source of the messages that they communicate. In addition, and again as opposed to artists, the job of communication designers must normally be free of the personal presence of the author. This is done to avoid noise in communications that are expected to put clients in touch with their intended audience. While it is commonplace to recognize the creator of a painting by its style, it is not desirable to recognize designers through their work, particularly when their presence creates noise in the interpretation of a message. However, we can often recognise a designer by his/her work. Another serious problem is following of design trends in visual communication, which is similar as in fashion design.

Frascara (2004) highlights that, today, designers have at their disposal an immense collection of visual resources that has been generated by a long tradition of art and design. The problem for the designer now is to avoid capricious selections and to develop a visual language that meets the needs of the project. This is one of the first challenges in the design process for visual communications.

According to Crilly (2015), the term "design fixation" is often used to refer to a set of phenomena, or is used more narrowly to refer to the way in which designers inadvertently 
carry over specific and unhelpful features from a previous example when they are designing something new. The term "fixation" has been used by psychologists to describe the variety of blocks that can impede insight, often resulting from the counterproductive effects of prior knowledge (Smith, 1995). Researching fixation of designers during their work is important for developing an understanding of what the barriers are to creative design and how those barriers might be avoided.

\section{Visual Communication Design}

The focus of this paper is visual communication design. The visual communication designer, according to Frascara (2004), works on the interpretation, organization and visual presentation of message. To understand visual communication design properly, we have to think more about actions than about objects. The emphasis should not be on the product, given that this is only a means. Essentially, the designer generates the communication by designing an event, an act in which the public interacts with the design. The objective of the designer is, therefore, the design of communicational situations. Further, the important issue is not the communicational act itself, but the impact that this has on the knowledge, the attitudes, and the behaviour of people. This makes clear the need to study the interaction between messages and people, not only the interaction of visual elements with one another, which has absorbed the attention of designers so much in the past. Visual composition is important, but it is only a tool, a way of organizing the communicational event. This communicational event happens over time-not only in space-and is loaded with complex human elements related to language, experience, age, knowledge, education, memory, cognitive style, preferences, expectations, desires, and other perceptual, intellectual, social, cultural, and emotional dimensions. In sum, the purpose of communication design is to affect the knowledge, attitudes, and behaviour of people - something that happens after the communication takes place (Frascara, 2004, p. 13).

For Frascara (2004), the final message-that is, the interpretation built by the public-is a cognitive /emotional/ operational unit that can only be divided for the purpose of studying it. The experience of the people exposed to the messages is holistic, and can only be predicted within a generous margin of uncertainty. Every communication in design involves a source, a designer, a medium, a code, a form, a content, a context, and a public (that builds a meaning, develops an attitude, and adopts a visible or internal behaviour). It also involves perceptual, 
emotional, and cognitive processes (denotative and connotative). Form and style always communicate. Every communication is affected by the different contexts that surround it.

Every design that competes with other visual stimuli (a poster in the streets, an ad in a magazine, a sign in a train station) must both attract and retain the attention of the viewer. To meet the first condition, the image must be strong enough to emerge clearly from its context. This is done through elements of form and content. The image must be visually strong, that is, it should have a high internal cohesion, and should at the same time differ from the context surrounding it. In addition, the content has to be relevant to the interests of the viewer. This last aspect, which, at first, seems to be connected only to withholding attention, also plays a significant role in attracting attention. Looking is not a passive act. We do not look in order to see; we look to understand, and to find what we want. Signification and relevance are major determinants for calling attention (Frascara, 2004, p. 58). However, if something attracts the attention of a viewer, it should be connected with the subject, the problem and not completely out of the context, which is usual in commercial advertising.

The designer should develop a checklist to bear in mind for all projects, adapting and extending that list according to the requirements of each case. The general list could be as follows: fitness to content, fitness to context, quality of concept, quality of form, legibility/visibility, craft, quality of medium, and also added should be quality of the research and power of the persuasive arguments.

All perception involves a search for meaning, and it is, in this sense, a communicational act or a search for communication. We could recognize two fundamental components in any perception: the search for meaning, and the construction of meaning based on the organization of the stimuli (Frascara, 2004, p. 64).

To perceive is not to receive information passively. To perceive involves searching, selecting, relating, organizing, establishing connections, remembering, identifying, defining hierarchies, judging, learning, and interpreting. The more organized the stimuli are in relation to the public's cognitive style, the easier it is to interpret them. This is why it is so important to use pertinent symbols in graphic messages and to organize them according to systems that are understandable by the public (Frascara, 2004, p. 68). Does a piece of design have to follow the rules of aesthetic harmony? 
According to Poynor (2017), we live in a time of cultural pluralism, after decades of mutually cancelling so-called "isms", in which any graphic outcome is potentially available for use, and there is nothing stopping us, apart from the constraints of fashion and taste, from jumping between wildly different aesthetic devices.

What matters most of all is a design's context. The way forward for progressive graphic designers is to ignore the insidious influence of fashionable stylistic memes, where the primary concern seems to be to impose on the graphic sphere a lack of true differentiation, and instead to pay close attention to the particularities of each project and what it is trying to communicate. This idea is certainly not new. The ideal of flexible practice is often stated as a goal for graphic design, although designers who proceed with this degree of freedom are in curiously short supply. Most designers tend to operate within strictly prescribed aesthetic limits. Nevertheless, a graphic method determined primarily by context has limitless potential; it could run - or rerun - forever because the everyday sites and contexts in which graphic design takes place are infinitely variable.

For Poynor (2017), graphic design as a visual language should express a multiplicity of viewpoints. It should be as changeable as written and verbal expression because anything less is a denial of visual communication's essential social function. The designer who is imaginatively open to the manifold possibilities of communication is already performing a vital social role (Poynor, 2017).

There are several reasons why aesthetics is a major concern in design:

- It creates attraction or rejection "at first sight"

- It communicates

- It affects the perceptual time an onlooker dedicates to a design

- It affects the memorization of the message

- It affects the active life of the design

- It affects, in a broad sense, the quality of the environment.

Attention and a good disposition on the part of the observer are necessary for communication to take place. The attention of the observer must be secured not only through the loudness of the stimulus or the relevance of the content, but also, and fundamentally, through the positive attraction that the stimulus generates (Frascara, 2004, p. 74).

It is not possible to understand the role of aesthetics without a context. It is not possible either to understand the function, the limitations, and the possibilities of design without 
putting this in the social, political, physical, cultural, and commercial contexts in which it operates (Frascara, 2004, p. 84).

However, aesthetic harmony is not always the designer's goal. As Poynor (2017) highlights, the broken forms, pictorial fragmentation and disharmony that anti-design revels in can be found from the controversial postmodern digital experimentalists of the 1990s, to punk graphics of the 1970s and early 1980s and, before that, in the cultural graphics of the 1960s, in art it goes back to early modernism and Picasso. We can say that this "calculated use of ugliness" in visual communication design as Poynor calls it, which is resistance to conventional and a search for a deeper truth, returns every now and then as a new (retro) style.

Images can be used to communicate in many ways, as they are very versatile and their reading can be conditioned by different factors. Images can have different cultural and social interpretations and these can be shaped by the contexts within which they are used. The cultural groups they are directed towards, the inclusion or exclusion of particular signs and symbols shared by a cultural group, the use or absence of conditioning agents such as wit and humour and appropriation of historical meaning, are all factors that might influence the meaning drawn from an image (Ambrose, Harris, 2010, p. 83). A design with a high aesthetic value will have more chance of being kept active in the mind of its public. Even after its function has passed-pieces of visual communication design of high aesthetic value keep on showing up in exhibitions and publications and continue to issue their message, they contribute positively to the image of those who generated it. However, it is necessary to ask oneself why many designs, especially in advertising, today are not of high aesthetic value, send banal messages and underestimate their public (see examples shown in figures 1 and 2).

\section{NE DIŽE SE. \\ NE DIŽE SE}

Fiksna kamata za cijelo vrijeme otplate stambenog kredita.

Figure 1. An example of a banal message in advertising from Wustenrot Croatia: The message of the first, provocative teaser phase (on the left) was: "It does not rise" (the bank interest) (Source: Pbs.twing.com, n.d.) 


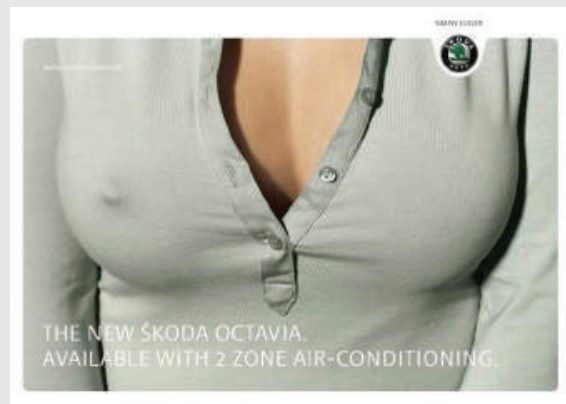

Figure 2. An advertising campaign for Skoda Octavia air conditioning system (Source: Pinterest, n.d.).

\section{Research Questions and Methodology}

Concerning many examples of low quality, cheap and dysfunctional package or product design, bad layout, wrong use of typography or bad organisation of information and visual imbalance of websites - internet portals, low quality of online advertising design and especially low aesthetic quality and banal messages in the field of visual communication design, our research questions are as follows:

RQ1: Do consumers get affected by quality of design in various design fields?

RQ2: Do consumers believe in messages sent by advertisements through different marketing communication media?

In the first stage of the research the task was to find out whether users notice design of products, services and visual communications and does the quality of design affect their choice of purchasing, choosing a website or an Internet portal, their desire to find out more about a product or a service.

The online research was conducted during May 2017 on a sample of 100 respondents of different ages. The questionnaire consisted of three assertions which had to be valued according to a 5-point Likert scale, from 1 (I do not agree at all) to 5 (I completely agree).

The first assertion: Product design, which implies its functionality, aesthetic value - beauty, quality, ease of handling and / or simplicity of the symbols, affects my choice when purchasing. 
The second assertion: Interface design, which implies logical structure and organization of information, readability of characters, colour and photo selection, aesthetic value, interactivity and easy search for information, affects my choice of web site / portal.

The third assertion: Design of advertisements, posters, and / or video commercials, which implies the originality of an idea, the tone of the message, the way of communication, and the overall aesthetic value, affects my desire to find out more about the product / service.

There were also general questions about respondent age, gender and qualifications.

\section{Analysis of Research Results}

The sample of respondents consisted of different age groups. While groups (18-25), (26-40) and (41-55) were well covered, there was lack of respondents over the age of 56 . Concerning qualification, the group of undergraduate was dominant. The gender of respondents does not give the real picture because there were $66 \%$ of women respondents.

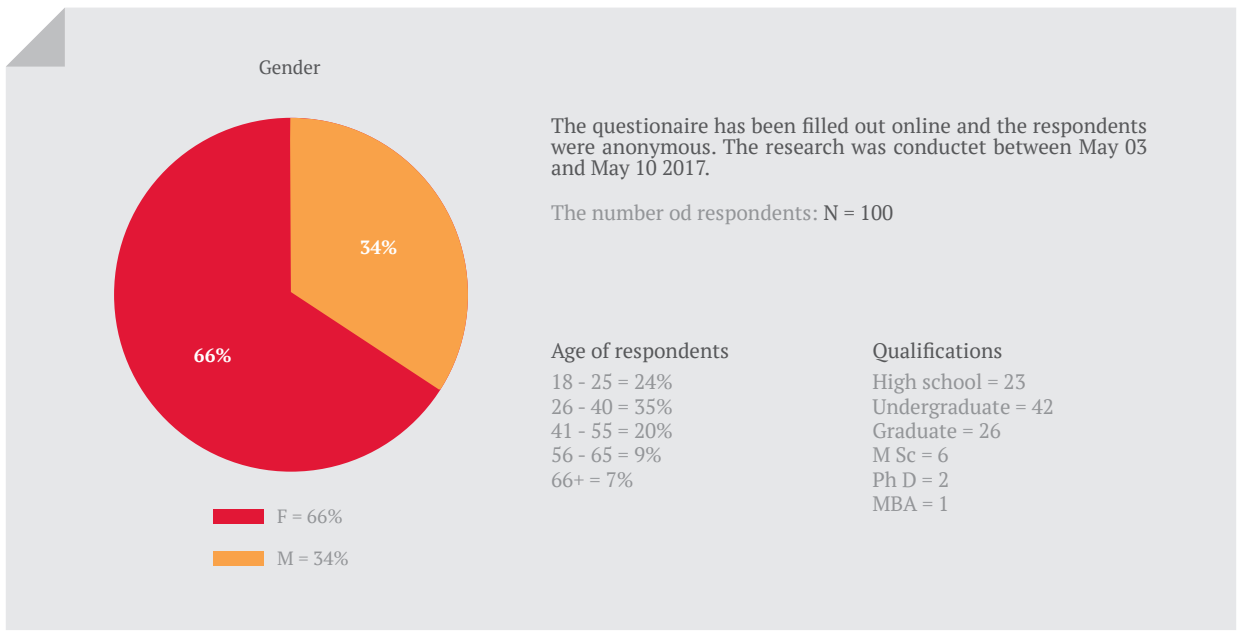

Figure 3. Personal data about respondents $(\mathrm{N}=100)$

The results of valuing the first assertion are shown in Figure 4 . More than $60 \%$ of respondents chose 5 points while $31 \%$ valued the assertion with 4 points. The mean value was 4.52 (standard deviation 0.78). 
Assertion no. 1. Product design, which implies its functionality, aestethic value - beauty, quality, ease of handling and / or simplicity of the symbols, affects my choice when purchasing.

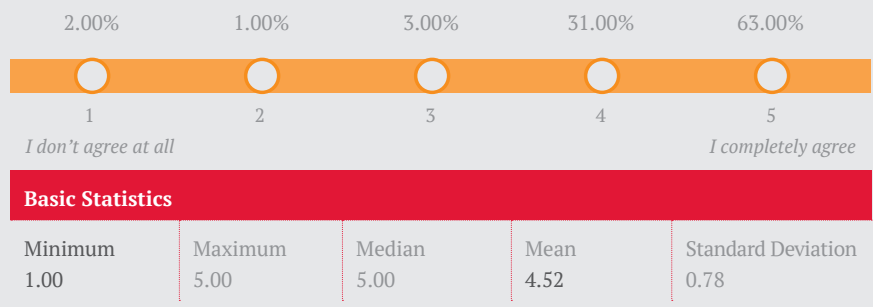

Figure 4. First assertion with results $(\mathrm{N}=100)$

The results of valuing the second assertion are shown in Figure 5 . While $45 \%$ of respondents chose 4 points, 37\% valued the assertion with 5 and the mean value was 4.13 (standard deviation 0.86).

Assertion no. 2. Interface design, which implies logical structure and organization of information, readability of characters, color and photo selection, aesthetic value, interactivity and easy search for information, affects my choice of web site / portal.

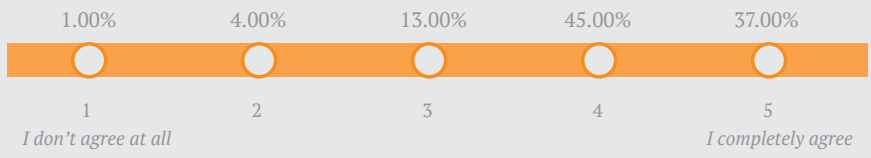

\begin{tabular}{l|l|l|l|l}
\multicolumn{2}{l|}{ Basic Statistics } & \multicolumn{2}{l}{} \\
\hline Minimum & Maximum & Median & Mean & Standard Deviation \\
1.00 & 5.00 & 4.00 & 4.13 & 0.86 \\
\hline
\end{tabular}

Figure 5. Second assertion with results $(\mathrm{N}=100)$

More than half of respondents, $54 \%$ chose 5 points - "I totally agree" - valuing the third assertion, and the mean value was 4.30 (standard deviation 0.93). The results can be seen in Figure 6. 
Assertion no. 3. Design of advertisments, posters, and / or video commercials, which implies the originality of an idea, the tone of the message, the way of communication, and the overall aesthetic value, affects my desire to find out more about the product / service.

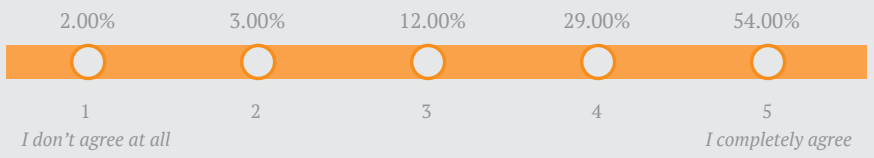

\section{Basic Statistics}

\begin{tabular}{l|l|l|l|l} 
Minimum & Maximum & Median & Mean & Standard Deviation \\
1.00 & 5.00 & 5.00 & 4.30 & 0.93
\end{tabular}

Figure 6. Third assertion with results $(\mathrm{N}=100)$

\section{Conclusion}

There are many examples of low quality in design works, especially in the field of "commercial" visual communication design, in Croatia, as well as in other countries. There is also a lack of research in the perception of design quality by its users - consumers in Croatia. We are interested in the reasons why marketing or design agencies use banal visual messages in advertising and marketing communication at large. Do creative directors (or perhaps their clients) underestimate the users, their taste, as well as their way of perception? Is appeal to sex or similar banal ways of communication with the audience the right solution for promoting different products and services and does it result with only short-term attention or long-lasting positive image and business success? Would it be possible that, in the future, visual communication design in the context of marketing communication gets closer to art and enriches our environment (as in the case of designing for culture and non-profit sector)?

The results of the online research show that design has a great impact on the public, users, consumers, regardless of whether it is about purchasing a product, choosing a website portal for information or attracting attention with an advertisement. 


\section{Limitations and Future Research}

The limitation of the conducted online research lies in the fact that a rather small number of respondents has been included and the sample of respondents had a much higher percentage of women, which does not represent the relevant sample for general conclusions about the subject. That is the reason why research should continue and be complemented, using qualitative methods.

Qualitative research about visual messages in the field of marketing communication is planned to be the subject of the second phase of the research: face to face interviews in focus groups of randomly chosen members of target consumers. Different examples of advertisements would be chosen and shown to the members of focus groups. Respondents would be asked to value the quality of messages, possible associations with the product they promote and their credibility.

The focus in the second stage of research will be on manipulation in advertising and other ways of visual communication, especially frequent use of appeal to sex. The effect of banal messages, created outside the context, on users/consumers and their decisions about purchasing the products, as well as the possible negative impact on brand image are going to be investigated. Interviews will also include a sample of designers and creative directors from marketing agencies, so that the problem could be viewed from multiple sides. 


\section{Reference List}

- Ambrose, G., Harris, P. (2010). Design Thinking. Switzerland: AVA Publishing.

- Almquist, J., Lupton, J. (2009). Affording Meaning: Design-Oriented Research from the Humanities and Social Sciences. Design Issues, 26 (1), 3-14.

- Berkowitz, M. (1987). The Influence of Shape on Product Preferences. In: M. Wallendorf, P. Anderson, P. (Eds.), Advances in Consumer Research, 14. UT: Association for Consumer Research. Retrieved from http://www.acrwebsite.org/search/viewconference-proceedings.aspx?Id=6765. 2 July 2017.

- Brown, T. (2009). Change by Design: how design thinking transforms organizations and inspires innovations. New York: HarperCollins Publishers.

- Candi, M. (2005). Design as an Element of Innovation. Island: Reykjavik University.

- Creusen, M. E. H., Schoormans, J. P. L. (2005). The different roles of product appearance in consumer choice. Journal of Product Innovation Management, 22 (1), 63-81.

- Crilly, N. (2015). Fixation and creativity in concept development: The attitudes and practices of expert designers. Design Studies, 38, 54-91. Retrieved from http://www.sciencedirect.com/science/article/pii/S0142694X15000137?via\%3Dihub. 2 July 2017.

- Dreyfuss, H. (1967). Designing for People. New York: Paragraphic Books.

- Frascara, J. (2004). Communication Design. Principles, Methods, and Practice. New York: Allworth Press.

- Kotler, P., Alexander Rath, G. (1984). Design: a powerful but neglected strategic tool. Journal of Business Strategy, 5 (2), 16-21, https://doi.org/10.1108/eb039054.

- Norman, D. A. (2002). Emotion \& Design: Attractive Things Work Better. Interactions, 9 (4), 36-42.

- Norman, D. A. (2004). Emotional Design. New York: Basic Books.

- Papanek, V. (1984). Design for Human Scale. New York: Van Nostrand Reinhold.

- Smith, S. M. (1995). Getting into and out of mental ruts: a theory of fixation, incubation, and insight. In: R. J. Sternberg, J. E. Davidson (Eds.), The nature of insight (pp. 229-251). Cambridge: The MIT Press.

- Stuart, F. I., Tax, S. (2004). Toward an integrative approach to designing service experiences. Lessons learned from the theatre. Journal of Operations Management, 22, 609-627.

- Ulrich, K. T., Eppinger, S. D. (2003). Product Design and Development. New York: McGrawHill/Irwin series in marketing.

- Yamamoto, M., Lambert, D. R. (1994). The impact of product aesthetics on the evolution of industrial products. The Journal of Product Innovation Management, 11 (4), 309-324.

\section{Internet Sources}

- Pinterest (n.d.). Retrieved from https://www.pinterest.com/pin/500603314801754940/. 17 June 2017.

- Poynor, R. (2017). Guest theoretician Rick Poynor: Social Reruns (zgraf 12). Retrieved from http://zgraf.hr/en/social-reruns-2/. 18 June 2017.

- Pbs.twimg.com (n.d.) Retrieved from https://pbs.twimg.com/media/C6U2kZVWQAAuwx-.jpg. 17 June 2017. 


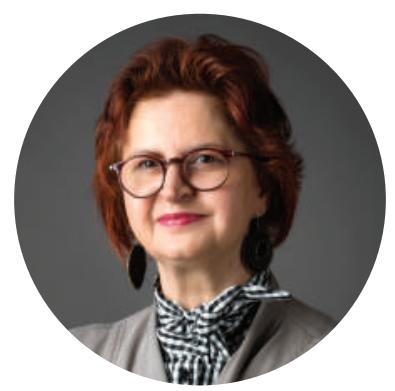

\section{Sanja Rocco}

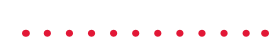

Sanja Rocco, M.Sc., is a senior lecturer at the Zagreb School of Business and Head of Marketing Department, teaching several courses: Promotion, Product Development and Design, Creative Design Thinking, Design and Innovation Management and Branding. She also gives lectures on Visual Communication as part of the graduate study programme "Managing Public Relations" at the Edward Bernays University College. She has professional experience as a manager and as an art director/ designer. She obtained her diploma at the Faculty of Architecture and master's degree at the Faculty of Economics and Business, University of Zagreb, and is currently a doctoral candidate at the Faculty of Economics and Business, University of Maribor. 